\title{
Ultrastructural Details of Cryptosporidium parvum Development in Calf Intestine
}

\author{
Mํㅡ José Rosales, Teresa Arnedo, Carmen Mascaró ${ }^{+}$
}

\author{
Departamento de Parasitología, Instituto de Biotecnología, Facultad de Ciencias, Universidad de Granada, \\ E-18071, España
}

Cryptosporidium parvum and C. muris appear to be different species found in calves, with different oocysts size and distribution on the gastrointestinal tract.

This work presents new images of C. parvum ultrastructure in calf intestine, mainly its development in nonmicrovillous cells and the presence of microtubular structures in the membrane enveloping the macrogamonts and immature oocysts.

Key words: Cryptosporidium parvum - ultrastructure - calf intestine - zoite - meronts - macrogamont microtubules

Bovine cryptosporidiosis was first described by Panciera et al. (1971). The first bovine ultrastructural descriptions appear in 1978, clearly showing an extracytoplasmatic but intracellular position in the epithelial cells (Pohlenz et al. 1978, Pearson \& Logan 1978). This position described by some authors as unique is commonly found in some species of the genera Eimeria, Epieimeria and Goussia which parasitize both freshwater and marine fish (Lukes 1992).

The differences between Cryptosporidium muris and $C$. parvum were well established by Upton and Current (1985) based on the different oocysts and sporozoite sizes, being $C$. muris oocysts larger.

Ultrastructural studies by different authors clearly showed morphological differences between Cryptosporidium isolated from mammals, namely the presence of mitochondria in C. muris, clearly demonstrated by Uni et al. (1987) but never detected by other authors in other isolates ascribed to $C$. parvum.

For several years we have been working with a strain of Cryptosporidium isolated from dairy cattle at a farm where almost $100 \%$ of suckling calves were spontaneously infected during the first two weeks of life. Oocysts size and morphology are similar to that of $C$. parvum. Extensive study has been performed on this isolate and we now have detailed information about its ultrastructural characteristics.

\footnotetext{
This study was supported by the CICYT through Projet PB95-1200.

+Corresponding author. Fax: +34-58-243174.

Received 19 November 1997

Accepted 25 June 1998
}

The present work focus on a better understanding of the ultrastructure of C. parvum.

\section{MATERIALS AND METHODS}

Histological samples for our electron microscopic study were recovered from a 7 day old calf (Holstein) killed after suffering signs of meningitis. Tissue samples were fixed in glutaraldehyde and processed for electron microscopy according to standard methods (Rosales et al. 1993a). Cryptosporidium infection was first detected in calf faeces by optical microscopy and afterwards by the histological study of lung and intestinal tissues.

\section{RESULTS AND DISCUSSION}

Developing Cryptosporidium forms were viewed by optic and electron microscopy both in small and large intestine. From the electron micrographs we have selected the one showing the most informative aspects of the parasite and of the host cell-parasite interactions.

Fig. 1 shows a zoite just attached to a Paneth intestinal cell. A three-membrane complex is tightly adhered to certain zones of the parasite (arrow). The three membrane layers show the same width, and a fourth more electrodense membrane appears at the apical end (arrowhead). A membrane fusion image is seen at the parasite-cell contact with some serrations at the right-hand corner. There is no indication of an envelope of host-cell origin in this form, although a dense band in the parasite-cell interface is clearly visible. In more differentiated merogonic forms (Fig. 2P,E), meronts are almost invariably enveloped by two membranes and also included in the two membrane units of presumably host origin and a vacuolate zone (known as feeder organelle) becomes evident in this region (Fig. 3F), but never so folded and organized as 


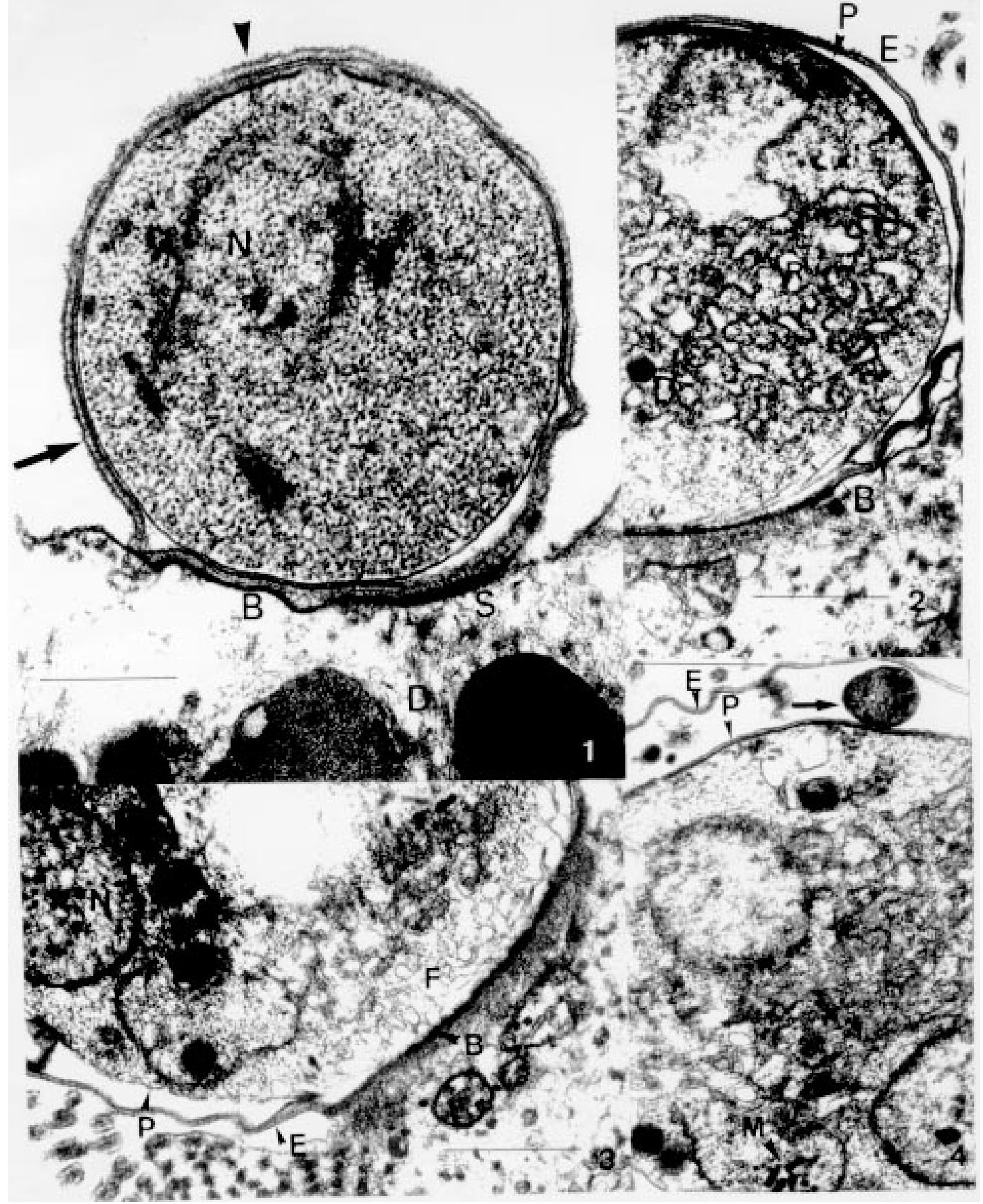

Fig. 1: Cryptosporidium zoite fixed to a Paneth cell. A three-membrane complex envelopes the protozoan (arrow) with a more electrondense fourth membrane at the apical end (arrowhead). D: dense granules in the apical cell cytoplasm. B: dense band in the parasite-cell interface. N: nucleus. S: serrations. Bar: $1 \mathrm{~mm}$. Fig. 2: meront fixed to an enterocyte. B: dense band in parasite-cell interface. D: dense granule. E: enveloping membranes. P: parasite membranes. R: rough endoplasmic reticulum. Bar $=1 \mathrm{~mm}$. Fig. 3: more differentiated meront. B: dense band. F: feeder organelle. E: enveloping membranes. P: parasite membrane. N: merozoite nucleus. Bar $=1 \mathrm{~mm}$. Fig. 4: portion of a meront showing a membrane bound structure (arrow). E: enveloping membranes. P: membrane pellicle. M: micronemes. Bar $=1 \mathrm{~mm}$. 

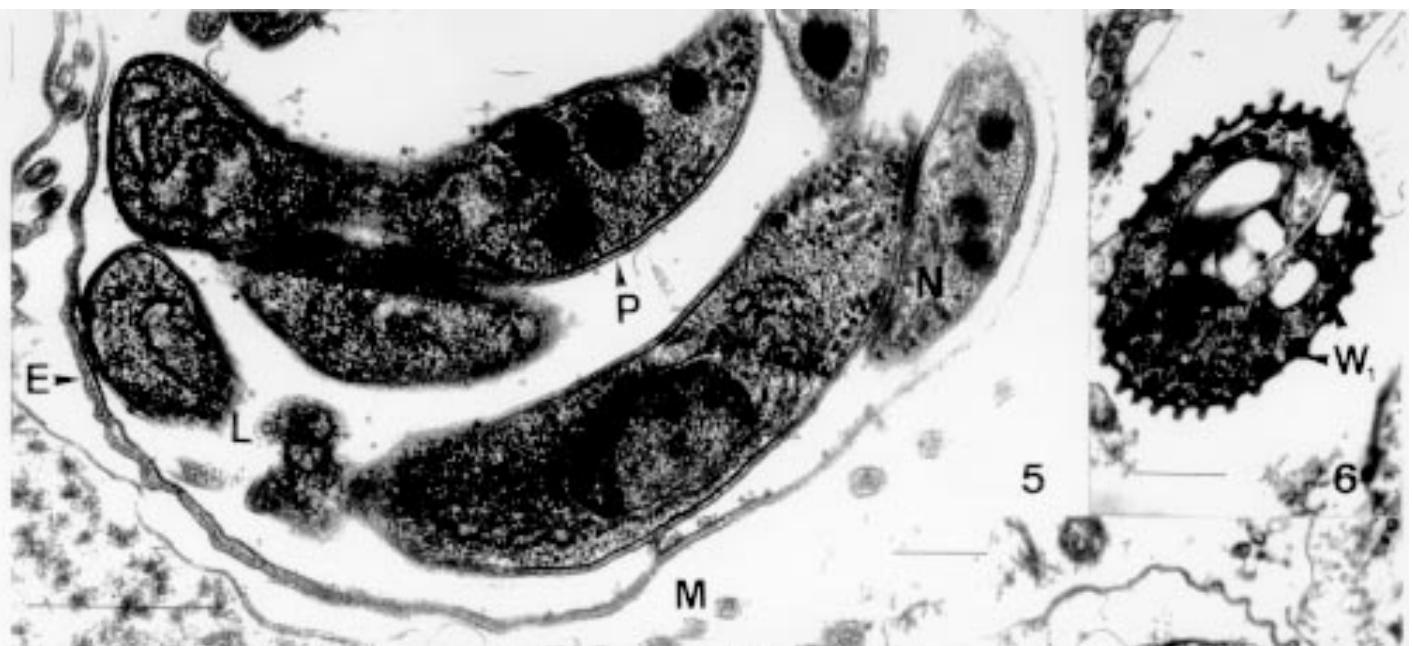

5

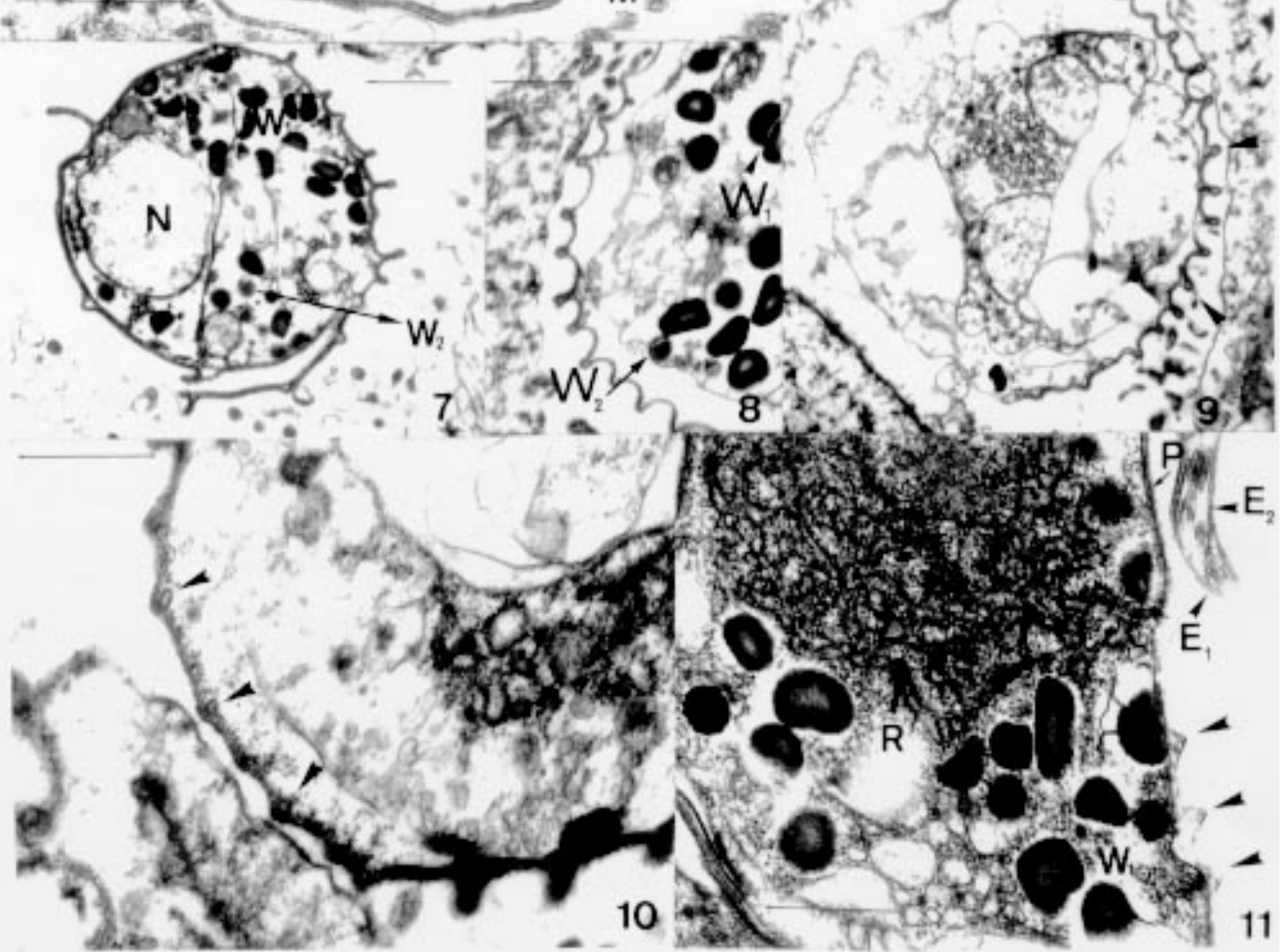

Fig. 5: portion of a mature type I meront. E: enveloping membranes with dense granular intermembrane material (arrow); L: longitudinal ridges in the pellicular merozoite membranes; M: microvilli; P: two membrane pellicle. Bar $=1 \mathrm{~mm}$. Fig. 6: section through a macrogamont showing an undulated contour. Wall-forming bodies type $\mathrm{I}\left(\mathrm{W}_{1}\right)$ adheres to the periphery. Bar $=1 \mathrm{~mm}$. Fig. 7: section through a macrogamont with an undulated contour. N: nucleus; $\mathrm{W}_{1}$ : wall-forming body type $\mathrm{I} ; \mathrm{W}_{2}$ : wall-forming body type II. Bar $=1 \mathrm{~mm}$. Fig. 8: portion of a macrogamont fixed to an enterocyte showing an undulating contour in some zones. $\mathrm{W}_{1}$ : wall-forming body type I; $\mathrm{W}_{2}$ : wall-forming body type II. Bar $=1 \mathrm{~mm}$. Fig. 9: free Cryptosporidium form in lumen intestine. Although its content is degenerated, the enveloping membranes are well preserved in a zone (arrows) showing a peculiar disposition. Bar $=1 \mathrm{~mm}$. Fig. 10: portion of a macrogamont growing in an enterocyte. Microtubular structures (arrows) are evident. Bar $=0.769 \mathrm{~mm}$. Fig. 11: portion of a macrogamont. Its enveloping membranes were accidentaly displaced by sample processing, and some microtubules (arrow) are visible on the parasite pellicle. $E_{1}$ : enveloping membranes of the macrogamont; $E_{2}$ :enveloping membranes of other adjacent Cryptosporidium form; $\mathrm{P}$ : parasite pellicle; R: rough endoplasmic reticulum; $\mathrm{W}_{1}$ : wall-forming body type I. Bar $=0.769 \mathrm{~mm}$. 
described by other authors (Fayer et al. 1990).

Membrane-bound structures are usual between the parasites and their envelopes (Fig. 4). When the merozoites are well formed, a dense granular intermembrane material is clearly visible (Fig. 5E, arrowhead). This material was described by Pohlenz et al. (1978), who did not believe that these membranes were of host origin. We also noticed that some Cryptosporidium forms had an undulated contour (Figs 6-9). Longitudinal and transverse cuts under higher magnification revealed fundamentally in macrogamonts and maturing oocysts, ordered microtubular structures (Figs 10, 11, arrowheads). This sort of structure, being a physical support, appears to offer strength to the developing parasite. Due to the absence of this microtubular support in the microvillous surface these microtubules may be of parasite origin, as they resemble the subpellicular microtubules in other coccidia.

Although in the last few years we have obtained many ultrastructural images of this Cryptosporidium in cultured MDCK cells (Rosales et al. 1993b), chick embryos (Rosales et al. 1992) and in calf tissues (Mascaró et al. 1993), we have never found, either in sporozoites or in merozoites cuts, micronemes arranged in parallel stacks or in zigzag patterns as so clearly described by other authors (Current \& Reese 1986, Liebler et al. 1986, Fayer et al. 1990, Bonnin et al. 1990, Flanigan et al. 1991, Aji et al. 1991, Rondanelli et al. 1993). In our isolate the micronemes are never orderly (Fig. 5) and thus provide a quite different ultrastructural image.

This isolate can be cultivated in MDCK cells (Rosales et al. 1993a) and in mouse peritoneal macrophages (Martinez et al. 1992), does not grow as well in chick embryos (Rosales et al. 1992) as does other $C$. parvum isolates (Current \& Long 1983), and the enzymatic studies revealed the absence of detectable hexoquinase (Entrala \& Mascaró 1997). To further characterize potential strain differences, it will be necessary to use standard methodologies to compare different isolates of $C$. parvum, at the ultrastructural as well as the immunological and enzymatic levels.

\section{REFERENCES}

Aji T, Flanigan T, Marshall R, Kaetzel CH, Aikawa M 1991. Ultrastructural study of asexual development of Cryptosporidium parvum in a human intestinal cell line. J Protozool 38: 825-845.

Bonning A, Salimbeni I, Dubremetz JF, Harly G, Chavanet P, Camerlynck P 1990. Mise au point d' un modèle expèrimental de culture in vitro des stades asexuès de Cryptosporidium sp. Ann Paras Hum Comp 65: 41-43.

Current WL, Long PL 1983. Development of human and calf Cryptosporidium in chicken embryos. J Infect Dis 148: 1108-1113.

Current WL, Reese NC 1986. A comparison of endogenous development of three isolates of Cryptosporidium in suckling mice. $J$ Protozool 33: 98108.

Entrala E, Mascaró C 1997. Glycolytic enzyme activities in Cryptosporidium parvum oocysts. FEMS Microbiol Let 151: 51-57.

Fayer R, Speer CA, Dubey JP 1990. General biology of Cryptosporidium, p. 1-29. In JP Dubey, CA Speer, R Fayer (eds), Cryptosporidiosis of Man and Animals, CRC Press, Boca Ratón, Fl.

Flanigan TP, Aji T, Marshall R, Soave R, Aikawa M, Kaetzel CH 1991. Asexual development of Cryptosporidium parvum within a differentiated human enterocyte cell line. Infec Immun 59: 234239.

Liebler EM, Pohlenz JF, Woodmansee DB 1986. Experimental intrauterine infection of adult BALB/c mice with Cryptosporidium sp. Infect Immun 54: 255-259.

Lukes J 1992. Life cycle of Goussia pannonica (Molnar, 1989) (Apicomplexa, Eimeriorina), an extracytoplasmatic coccidian from the White Bream Blicca bjoerkna. J Protozool 39: 489-494.

Mascaró C, Arnedo T, Rosales MJ 1993. Respiratory cryptosporidiosis in bovine. J Parasitol 80: 334-336.

Martinez F, Mascaró C, Rosales MJ, Diaz J, Cifuentes J, Osuna A 1992. In vitro multiplication of Cryptosporidium parvum in mouse peritoneal macrophages. Vet Parasitol 42: 27-31.

Panciera RJ, Thomassen RW, Garner FM 1971. Cryptosporidiosis in a calf. Vet Pathol 8: 479-484.

Pearson GR, Logan EF 1978. Demonstration of cryptosporidia in the small intestine of a calf by light, transmission electron and scanning electron microscopy. Vet Record 103: 212-213.

Pohlenz J, Bemrick WJ, Moon HW, Cheville NF 1978. Bovine cryptosporidiosis: a transmission and scanning electron microscopic study of some stages in the life cycle and of the host-parasite relationship. Vet Pathol 15: 417-427.

Rondanelli EG, Scaglia M, Gatti S 1993. Atlas of $\mathrm{Hu}$ man Protozoa, Masson, Millano, 556 pp.

Rosales MJ, Mascaró C, Osuna A 1992. New findings during Cryptosporidium parvum development in the chick embryo. J Infect Dis 165: 789-790.

Rosales MJ, Cifuentes J, Mascaró C 1993a. Cryptosporidium parvum: culture in MDCK cells. Exp Parasitol 76: 209-212.

Rosales MJ, Mascaró C, Osuna A 1993b. Ultrastructural study of Cryptosporidium development in Madin-Darby canine kidney cells. Vet Parasitol 45: 267-273.

Uni S, Iseki M, Maekawa T, Moriya K, Takada S 1987. Ultrastructure of Cryptosporidium muris (strain RN 66) parasitizing the murine stomach. Parasitol Res 74: $123-132$.

Upton SJ, Current WL 1985. The species of Cryptosporidium (Apicomplexa: Cryptosporidiidae) infecting mammals. J Parasitol 71: 625-629. 